nephron

Experimental

Nephrology

and Genetics
Nephron 2015;130:191-199

DOI: $10.1159 / 000433566$
Received: March 26, 2015

Accepted: May 25, 2015

Published online: June 25, 2015

\title{
Organoid Models and Applications in Biomedical Research
}

\author{
Christodoulos Xinaris $^{a}$ Valerio Brizi ${ }^{a} \quad$ Giuseppe Remuzzi ${ }^{a, b}$ \\ aIRCCS - Istituto di Ricerche Farmacologiche 'Mario Negri', Department of Molecular Medicine Bergamo, and \\ ${ }^{b}$ Unit of Nephrology and Dialysis, Azienda Ospedaliera Papa Giovanni XXIII, Bergamo, Italy
}

\section{Key Words}

Organoids · Dissociation reaggregation systems .

Pluripotent stem cells . Three-dimensional cultures .

Modelling of development and disease $\cdot$ Regenerative medicine

\begin{abstract}
Recent technical advances in the stem cell field have enabled the in vitro generation of complex structures resembling whole organs termed organoids. Most of these approaches employ three-dimensional (3D) culture systems that allow stem cell-derived or tissue progenitor cells to selforganize into 3D structures. These systems evolved, methodologically and conceptually, from classical reaggregation experiments, showing that dissociated cells from embryonic organs can reaggregate and re-create the original organ architecture. Since organoids can be grown from human stem cells and from patient-derived induced pluripotent stem cells, they create significant prospects for modelling development and diseases, for toxicology and drug discovery studies, and in the field of regenerative medicine. Here, we outline historical advances in the field and describe some of the major recent developments in 3D human organoid formation. Finally, we underline current limitations and highlight examples of how organoid technology can be applied in biomedical research.

(c) 2015 S. Karger AG, Basel
\end{abstract}

\section{Introduction}

Stem cells (SCs) offer enormously promising prospects for research and therapy. Today, several cell types can be generated in vitro due to the astonishing progress that has been made in isolating and handling cells from various tissues $[1,2]$ and, even more importantly, due to the ability to change cell identity by reprogramming [3] and re-differentiating somatic cells. However, because organs and tissues are three-dimensional (3D), important aspects influencing organogenesis are missing in conventional two-dimensional (2D) cultures. This problem has led to the development of 3D systems that enable the creation and growth, in vitro, of miniature organs called organoids, capable of developing organotypically and exerting organ-specific functions.

Organoids are usually generated from progenitor cells (PCs), which are either isolated from embryos or derived from pluripotent stem cells (PSCs) (fig. 1). These approaches are the conceptual evolution of traditional reaggregation experiments with embryonic tissues, demonstrating that aggregates of progenitor cells can differentiate and self-organize into 3D structures typical of early organogenesis $[4,5]$. Most current technologies involve exogenous tissue patterning using growth factors that drive particular cell identities, and extracellular matrix (ECM) gel embedding, followed by a reaggregation to

\section{KARGER 125}

(c) 2015 S. Karger AG, Base

$1660-8151 / 15 / 1303-0191 \$ 39.50 / 0$

E-Mail karger@karger.com

www.karger.com/nef
Dr. Christodoulos Xinaris

Department of Molecular Medicine, Laboratory of Cellular Biology and Regenerative Medicine, IRCCS - Istituto di Ricerche Farmacologiche 'Mario Negri', Centro Anna Maria Astori, Science and Technology Park Kilometro Rosso

Via Stezzano, 87, IT-24126 Bergamo (Italy), E-Mail christodoulos.xinaris@marionegri.it 


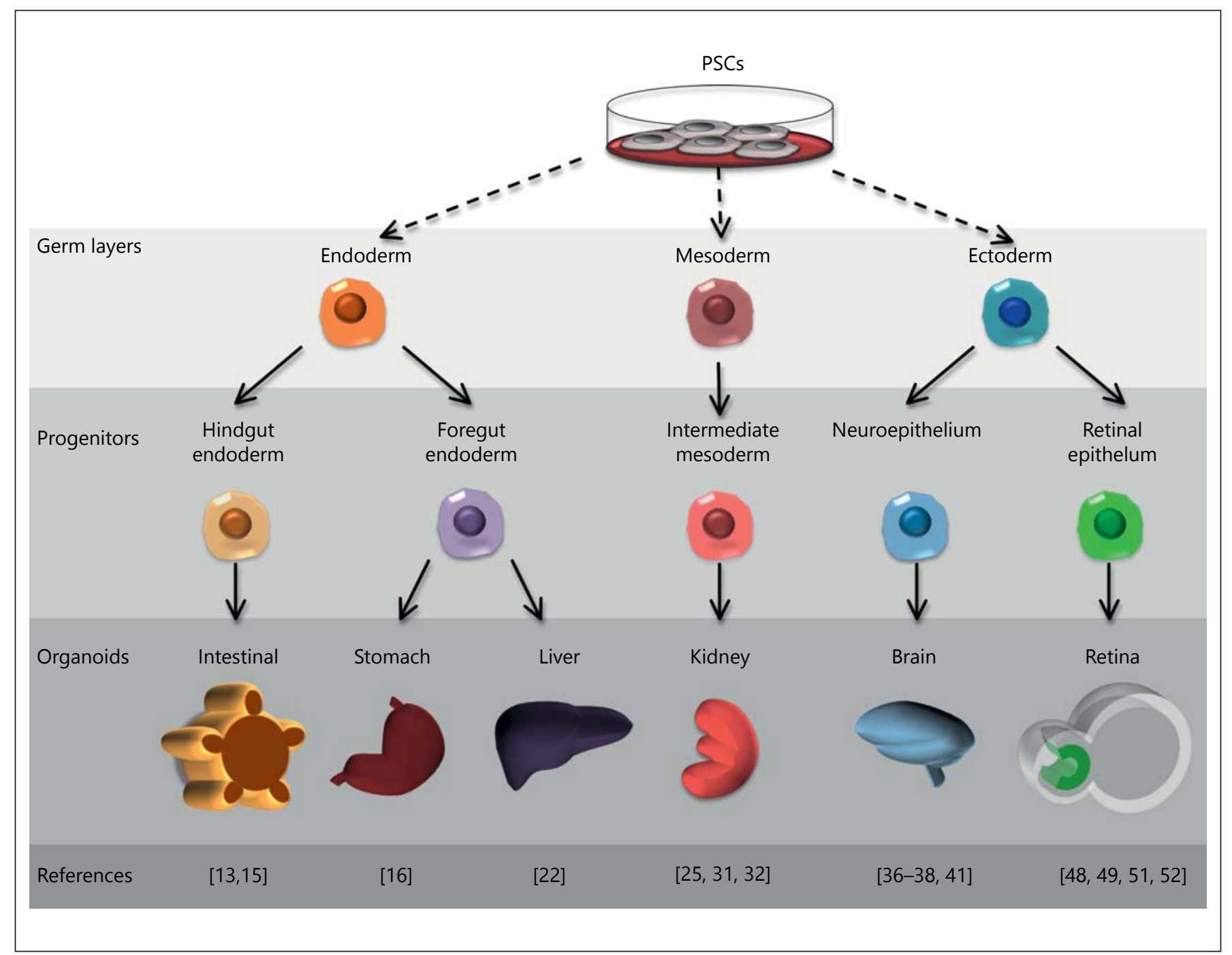

Fig. 1. Schematic representation of organoid generation from PSCs. For each class of organoid, this figure shows the germ layer of origin and the main progenitor cell identities or epithelia that can be generated from PSCs by using the in vitro differentiation protocols. These protocols recapitulate the developmental condi- tions, in terms of ECM and molecular environment, to which ESCs are normally exposed during in vivo organogenesis. More details of PSC differentiation strategies, culture conditions and growth factors used to derive organ-specific progenitor cells are described in the text. stimulate cell movement and create self-organized 3D tissue.

Thus, unlike 2D cell cultures, organoid systems enable 3D cell growth, movement, and differentiation, making this technology an effective model for understanding organ development, tissue morphogenesis and the genetic or molecular basis of diseases. In the future, they may also be employed in drug-testing studies and tissue replacement therapy.

Below we describe major recent advances in organoid technology.

\section{Gut Organoids}

The vertebrate digestive tract is composed of multiple organs that arise from a common primitive gut tube that extends from the mouth to the anus. The gut tube is formed by the endodermal layer folding [6] that is subdivided into three regions, the foregut, midgut and hindgut regions, each of which generates specific organs at predetermined times during embryonic development. The foregut gives rise to the pharynx, esophagus, stomach, liver, pancreas, lungs, and part of the duodenum. The 
midgut generates the remaining part of the duodenum, the jejunum, the ileum, and portions of the large intestine. The hindgut develops into the remainder of the large intestine, excluding a portion of the anal canal [7].

The Clevers group $[8,9]$ first demonstrated intestinal 3D organoid formation from mouse LGR5-expressing intestinal SCs that grew to form crypt-villus structures and all major cell-types of the gut in a laminin-rich Matrigel supplemented with EGF, Wnt agonist (R-spondin-1) and Noggin (BMP inhibitor). Interestingly, intestinal organoid technology has already been used as a potential platform for personalized medicine approaches, as demonstrated by the forscolin-induced human organoid swelling assay that enables the analysis of individual drug responses in cystic fibrosis [10]. Using LGR-5-expressing SCs again, this time isolated from the colon, Sato et al., grew similar human and mouse colon organoids [11]. These adult-derived mouse organoids were also able to integrate into superficially damaged mouse colon to reconstitute a single-layered epithelium with self-renewing, functional and histologically normal crypts [12].

Similar principles have recently been applied to generate intestinal organoids from PSCs of human origin. Spence et al. directed both human embryonic stem cell (hESC) and human-induced pluripotent stem cell (hiPSC) monolayers to form definitive endoderm using Activin A followed by 3D hindgut spheroid formation in the presence of FGF4 and Wnt3a [13]. Subsequently, these PSCderived spheroids were further cultured in a pro-intestinal culture system as described by Sato et al. [9] to form organoids consisting of a polarized, columnar epithelium that was patterned into villus-like structures and cryptlike proliferative zones, containing LGR5-expressing SCs, functional enterocytes, as well as goblet, Paneth and entero-endocrine cells. Remarkably, these PSC-derived intestinal organoids also developed a mesenchymal layer and intestinal subepithelial myofibroblasts, as well as smooth muscle cells and fibroblasts at later stages. Thus, the simultaneous development of intestinal epithelia and mesenchyme indicates highly coordinated interaction between the different germ layers in organoid morphogenesis [13].

By using this culture system as a model for studying human intestinal development, the authors further documented that the combined activity of Wnt3a and FGF4 is required for hindgut specification, whereas FGF4 alone is sufficient for promoting hindgut morphogenesis. Moreover, this system has been applied to investigating loss-of-function mutations in NEURG3, which underlies congenital malabsorptive diarrhea, presumably due to a lack of intestinal entero-endocrine cells [14]. Indeed, experiments with adenoviral-mediated overexpression and shRNA-mediated knockdown of NEURG3 demonstrated that intestinal entero-endocrine cell development is highly dependent on NEURG3 expression [13].

More recently, these organoids were transplanted into immunocompromised mice to develop mature epithelium and mesenchyme that contained differentiated intestinal cell lineages, functional brush-border enzymes, and subepithelial and smooth muscle layers. Transplanted intestinal tissues also demonstrated the digestive function, as shown by permeability and peptide uptake studies, and were able to respond to systemic signals from the host mouse following ileocecal resection [15].

Recently, McCracken et al. [16] reported the first generation of 3D human gastric organoids through directed in vitro differentiation of hESCs and hiPSCs. The authors recapitulated in vivo human stomach development by inducing first the PSCs to form definitive endoderm spheroids, which were subsequently stimulated by retinoic acid to generate the foregut. To permit $3 \mathrm{D}$ growth and further differentiation, spheroids were transferred into a retinoic acid-supplemented Matrigel culture, leading to the formation of domains with gastric mucous and endocrine cells, and LGR5-expressing SCs. Notably, to study the aetiology of Helicobacter pylori-mediated disease, they injected the bacterium directly into the lumen of the organoids, and observed that the virulence factor CagA bound and activated the c-Met receptor, inducing epithelial proliferation. This epithelial pathophysiological response makes the organoids a promising model for human gastric disease.

\section{Liver Organoids}

The liver has endodermal origins, arising from an outgrowth of the foregut ventral wall that develops into a liver bud structure [17]. Hepatic endoderm cells, known as hepatoblasts, delaminate from this bud, invade the surrounding mesenchyme and give rise to both hepatocytes and bile duct cells, while the mesenchyme provides fibroblasts, hepatic stellate cells and sinusoidal endothelial cells [18]. The generation of the liver bud is accompanied by the development of the hepatic vasculature, which forms through a combination of angiogenesis and vasculogenesis, and eventually becomes the major fetal hematopoietic organ. Thus, liver development depends on the delicate orchestration of signals between endodermal ep- 
ithelial, mesenchymal, and endothelial progenitors prior to blood perfusion.

Early developmental studies demonstrated that dissociated cells from the chick embryonic liver can reaggregate and organize into secretory units typical of the liver and consistent with the formation of functional bile ducts. Within the parenchyma of reconstituted tissues, hematopoietic islands that produced various types of blood cells were also present [19]. Recent advances have shown that a mouse PC population that appears near bile ducts following liver damage can be expanded clonally as organoids in 3D cultures over several months. These clonal organoids can also be induced to differentiate in vitro, and to generate functional hepatocytes upon transplantation into $\mathrm{Fah}^{-1-}$ mice (a model for tyrosinemia type I liver disease) [20], improving animal survival. Likewise, human bile duct cells can be expanded in vitro as bipotent progenitor cells into 3D organoids, and converted into functional hepatocyte cells either in vitro or upon transplantation. Notably, these organoids can be expanded from $\alpha-1$ antitrypsin deficiency and Alagille syndrome patients and mimic the in vivo pathology, creating significant opportunities for disease modelling and personalized medicine studies [21].

Starting with PSCs, Takebe and colleagues have recently generated tissues reminiscent of human liver buds [22]. In order to recapitulate early organogenesis, the authors cultivated hiPSC-derived endodermal cells with human umbilical vein endothelial cells and human mesenchymal stem cells in Matrigel to generate 3D liver buds with gene expression patterns very similar to those of primary fetal livers. It is noteworthy that soon after transplantation into a cranial window mouse model, the liver buds connected to the host vasculature, matured into adult-like liver tissues, and performed liver-specific functions such as serum albumin production and human-specific drug metabolism. Finally, transplanting human liver buds improved mouse survival after drug-induced liver failure.

While several unanswered questions remain, such as whether a direct or indirect mechanism underlies the observed therapeutic effect, this liver-bud transplantation seems to be a readily translatable approach for eventually treating liver insufficiency.

\section{Kidney Organoids}

The metanephric kidney has mesodermal origins and develops at the most posterior part of the trunk [23-25]. Its organogenesis begins with the specification of the kid- ney-precursor tissue intermediate mesoderm (IM), which progressively extends in a rostral-caudal direction, and gives rise to both the nephric duct (ND) epithelium and the metanephric mesenchyme (MM) [26]. The ureteric bud (UB) evaginates from the ND as an epithelial outgrowth that invades and interacts with the nearby MM to develop the branched collecting duct system. At the same time, mature nephrons and other MM derivatives develop through progressive MM condensation, epithelialization and differentiation regulated by UB branching and signalling [26].

As previously shown for the other organs, evidence that kidney tissue may be capable of self-organization comes from early reaggregation experiments. Pioneering studies by Auerbach and Grobstein demonstrated that by reaggregating cell suspensions from MM and embryonic dorsal spinal cord, a potent tubule-inductor, it was possible to generate tissues containing rudimental nephron-like tubular structures [4]. Significant progress in the field has been made through the development of a method that allows a simple suspension of embryonic kidney cells to self-organize in vitro into 'tissue' containing immature nephrons and UBs, without the use of any exogenous tissue [27]. However, the brief survival time of organ cultures in vitro, and most importantly the insufficiency of these systems to support the development of vascularised glomeruli (the filtering unit of the kidney), did not allow for further maturation into a state resembling adult kidneys. By building on this method, an optimized reaggregation system has allowed renal organoids to mature in vivo, using suspensions of embryonic kidney cells [28]. When transplanted under the renal capsule of athymic rats, these tissues became vascularized, grew further and performed kidney-specific functions, including blood filtration and tubular reabsorption of macromolecules, and the production of erythropoietin. By integrating electron microscopy analysis and macromolecular tracing experiments, the authors further documented that organoids could recapitulate, in vivo, the complex 3D filtering structure of glomerular slits and accomplish selective glomerular filtration [29]. Moreover, this technology was applied to generate $3 \mathrm{D}$ chimeric organoids from human amniotic fluid stem cells and mouse embryonic kidney cells that engrafted in vivo and grew to form vascularized glomeruli and tubular structures [30].

The above studies may suggest that if kidney PCs or mature cell types can be derived from PSCs and exposed to defined conditions, they can subsequently spatially self-organize in order to generate $3 \mathrm{D}$ renal tissues. 
Xia et al. have recently described an efficient and rapid protocol for the directed differentiation of hESCs and hiPSCs into UB progenitor-like cells in four days [31]. In the first 2 days, PSC clusters cultured on Matrigel were exposed to BMP4 and FGF2 signaling to induce mesodermal commitment, whereas on the following 2 days, cells were induced to acquire a late IM/UB-like phenotype in the presence of BMP2, retinoic acid and Activin A. To allow further maturation, differentiated cells were co-cultured with mouse embryonic kidney cells to form 3D chimeric organoids in which they showed integration into developing chimeric UB structures. Accordingly, given the absence of MM marker expression, these cells did not show any integration into the MM compartment [31].

Taguchi et al. derived MM cells [25] from both mouse ESCs (mESCs) and hiPSCs by first defining both the IM specification and MM and UB developmental origin, and then mimicking them in vitro. Initially, they discovered through lineage analysis that brachyury $(\mathrm{T})$-positive posterior mesoderm gives origin to the MM, whereas T-negative anterior mesoderm gives rise to the UB. Then, they optimized a differentiation protocol to induce MM progenitors from hPSCs. EBs were initially induced with Activin A, followed by exposure to BMP4 and the Wnt signalling agonist CHIR99021, leading to posterior mesoderm differentiation. Finally, the application of retinoic acid, followed by FGF9, stimulated the cells to assume a MM identity. When co-cultured with embryonic spinal cord, MM progenitors in the induced EBs showed the ability to further differentiate and develop proximal and distal tubules and glomerular-like structures containing cells positive for podocyte and foot process markers. When the induced mouse EBs were co-transplanted with spinal cords under the kidney capsule, they developed vascularized glomeruli containing red blood cells, demonstrating connection to the host circulation.

Almost simultaneously with these studies, Takasato et al. developed a differentiation protocol for the stepwise synchronous induction of both UB and MM starting with hESCs grown in 2D and exposed to chemically defined conditions that recapitulated those of normal kidney organogenesis [32]. First, hESCs were differentiated into the primitive streak, the progenitor population for both mesoderm and endoderm, by using either Activin A/ BMP4 stimulation or, alternatively, CHIR99021. As IM normally arises from the posterior primitive streak, they induced IM differentiation through FGF9 exposure. Subsequently, IM cells were exposed to FGF9/BMP7/retinoic acid treatment or were deprived of any growth factors, giving rise to $\mathrm{UB}$ and $\mathrm{MM}$ progenitors in both of the strat-

Creating Miniature Organs in vitro egies applied. Re-aggregation after dissociation of the initial monolayer cultures upon UB and MM commitment allowed the formation of small, self-organized kidney organoids. Finally, when renal progenitors were reaggregated with dissociated mouse embryonic kidneys, they generated chimeric organoids in which renal progenitors integrated into all developing renal structures, including the ureteric epithelium, renal vesicles, nephron progenitor mesenchyme, and renal stroma.

Remarkable future advances in kidney tissue engineering might be made possible by the recombination of the UB progenitor cells from the Belmonte group with the MM progenitors from the Nishinakamura group, to test whether starting with high-purity renal PC populations derived from different types of PSCs can drive organogenesis in vitro.

\section{Brain Organoids}

The nervous system derives from the neural ectoderm [33], which forms the neural plate, a flat lamina of ectodermal cells located dorsally in the embryo that progressively forms a cylindrical epithelial structure known as the neural tube. Along the ventral-dorsal and rostral-caudal axes, a rigorous spatio-temporal gradient of morphogens allows the epithelial tube to subdivide into four major regions: the prosencephalon (forebrain), mesencephalon (midbrain), and rhombencephalon (hindbrain), and the spinal cord. Secondary vesicles emerging from the prosencephalon give rise to the telencephalon (cerebral hemispheres) and diencephalon (thalamus and hypothalamus).

The neurons and glia of the CNS are generated from multipotent neural stem cells (NSCs) that reside rostrocaudally in the neural tube [34]. Through a series of initially symmetrical, and then asymmetrical divisions, NSCs give rise to self-renewing progenitors and more differentiated cell types, including neurons and intermediate progenitors. These more differentiated cells then migrate outward from the native NSCs' domains to develop multi-layered structures such as the medulla, the optic tectum, and the cerebral cortex.

Pioneering reaggregation studies using cells dissociated from the brains of E6-9 chick embryos demonstrated that this organ retains an intrinsic self-organizing capacity [35]. When taken at earlier stages of brain development, chick neural progenitors self-organized to form neuro-epithelial cell clusters organized radially around a lumen that resembled the neural tube. These classic ex- 
periments suggested that if neuro-epithelium can be derived from PSCs, spontaneous self-organization into 3D structures is likely to occur.

Directed in vitro differentiation of PSCs toward a cortical neuron fate revealed that these cells display a 'default' propensity for neural differentiation when maintained under minimal culture conditions. First, Watanabe et al. achieved the differentiation of floating mESC aggregates into telencephalic precursors using a serumfree culture, known as SFEB (serum-free, floating culture of embryoid body-like aggregates), in combination with 5-day exposure to Wnt and Nodal antagonists [36]. Then by optimizing this SFEB culture system, the same group derived human telencephalic precursors that self-organized into rosetted structures reminiscent of early cortical development [37]. The key configuration in these experiments was the rapid aggregation of hESCs to constitute a SFEB culture in medium containing ECM components, which yielded polarized neuro-epithelia with apical-basal polarity that further subdivided into the characteristic ventricular and subventricular PC zones. These PCs generated different cortical neuron classes in the appropriate temporal order, resembling that observed in the E11.5 mouse cortex. In addition, these neurons showed clear signs of maturation, including fast-wave $\mathrm{Ca}^{2+}$ oscillations [37]. This method has been further improved in a more recent study [38] describing a multilayered structure including neuronal and progenitor zones in the proper apical-basal order as seen in the human foetal cortex in the early second trimester.

Other brain regions can also be generated by mimicking endogenous patterning with growth factors. Previously, a variety of media conditions were used to produce different CNS regions from mESCs including subpallial patterning [39] and adeno-hypophysis [40], which may also soon be replicated using hPSC sources. Thus, stimulating the neuro-ectoderm through an EB stage and then applying specific growth factors could generate organoids for various individual brain regions.

Recently, researchers established a method that allows for the development of different brain regions in the same organoid [41]. This approach began with EBs, but no growth factors were added to drive particular brain region identities. The method was influenced by the intestinal organoid protocol, that is, by embedding the EBs in $3 \mathrm{D}$ ECM. The ECM promotes the outgrowth of large buds of neuro-epithelium, which then expand and develop into various brain regions, including the forebrain, hindbrain, dorsal cortex, prefrontal cortex, hippocampus, the choroid plexus occipital lobe, and the retina, leading to the term 'mini-brains'. To model the severe early onset brain condition microcephaly, the authors used iPSCs from a patient with a truncating mutation in CDK5RAP2 - a gene crucial for PC-state maintenance during development. These hiPSC-derived 3D organoids displayed rare neuro-epithelial PC zones and large domains of differentiated and mature neurons, suggesting that premature differentiation causes the in vivo establishment of the diseased phenotype, a conclusion that was further supported through overexpression and knockdown effects of CDK5RAP2 on organoid development.

Altogether these results provide access to a broad range of human CNS structures for functional studies and to clarify developmental pathways of the brain. Furthermore, brain organoids from patient-derived or genetically modified-hiPSCs could be a powerful tool for CNS disease modelling.

\section{Retinal Organoids}

The retina is the light-receptive region of the eye and derives from the neural ectoderm. Retinal primordia arise from the diencephalon and evaginate laterally, forming pseudostratified neuro-epithelia, termed optic vesicles (OVs) [42]. The distal portion of each OV becomes the sensory neural retina (NR; sensorial tissue), whereas the proximal portion gives origin to a monolayered tissue, the melanin-producing retinal pigment epithelium (RPE; supporting tissue of the NR) [43]. The OVs then undergo invagination at their distal portion [44] to form the optic cup (OC), with the NR and RPE as its inner and outer walls, respectively [42]. The NR contains PCs that differentiate into ganglion cells, photoreceptors (rods and cones) and supportive cell types, all spatially arranged into distinct layers forming the characteristic laminated retina [42].

The vertebrate retina has always been considered one of the most powerful reaggregation models in tissue engineering studies for investigating the basis of neural layer development [45]. A plethora of experiments in chick embryos has documented that retina have a remarkable capacity to reconstitute different types of spheres with almost complete arrangement of retinal layers [46, 47], and, as in other organoid approaches, this laid the groundwork for the development of PSC-derived retinal organoids.

The first study performed with PSCs to generate retinal organoids was by Eiraku et al. [48], documenting that 
the retinal epithelium can be generated efficiently by using 3D floating EB-like aggregates from mESCs cultured in low serum media and ECM components. Under these conditions, aggregates spontaneously formed hemispherical hollow vesicles - similar to the OVs - of which the proximal portion differentiated into pigment epithelium, whereas the distal portion progressively folded inward to form a shape reminiscent of the embryonic OC. These OC-organoids displayed proper markers of NR and RPE, and retinal stratification with proper apical-basal polarity, and underwent morphological tissue shape changes that mimic the stepwise evagination and invagination of the OC in vivo.

Astonishingly, when human organoids were formed, the size of the OC was larger than in the mouse cultures, reflecting species differences and indicating that tissue scaling is an intrinsic property of mouse versus human eye field cells [49]. Moreover, the hESC-derived retinal organoids had a thicker NR that spontaneously curved in an apically convex manner not observed in mESC cultures, and showed apical nuclear positioning. Human-derived retinal tissues required more time to develop; neural epithelium was multilayered and composed of many differentiated rods and cones, while cone differentiation was not observed in mESC cultures. This difference is consistent with the diverse visual skills of the two species due to their habits: in in vivo mouse retinas, there are few cones because mice are essentially nocturnal animals, whereas in human retinas they are numerous because they are crucial for colour vision during the daytime [50].

More recently, Assawachananont et al. [51] optimized the above protocol [48] by adding a retinoic acid receptor antagonist and increasing the knockout serum percentage to produce higher quantities of NR tissue for transplantation. Mouse ESC- or iPSC-derived 3D retinal sheets differentiated into various retinal cell types and mature photoreceptors that formed the outer nuclear layer of the retina (the light-detecting portion of the eye), in the subretinal space of severely degenerating mouse host retina, potentially suggesting a new retinal tissue transplantation therapy for advanced retinal degenerative diseases.

Taking a different approach, Zhu et al. induced the formation of polarized neuro-epithelial cysts by embedding small clusters of hESCs into a Matrigel supporting $3 \mathrm{D}$ epithelial cyst formation in the presence of the neural induction medium N2B27 [52]. In the absence of growth factors, these cysts acquired an eye-like identity that was capable of generating the NR when plated onto transwell filters, whereas in response to Activin A they differentiated into RPE.

Creating Miniature Organs in vitro
Therefore, 3D PSC-derived retinal tissues recapitulate the main aspects of retinal development, providing an opportunity to generate tissues for medical applications as well as a valuable tool for clarifying cell behaviours and mechanisms during retinal morphogenesis.

\section{Conclusions}

Three-dimensional culture methodologies, including the supply of ECMs together with reaggregation techniques and the identification of inductive factors that can direct hPSCs along a specific lineage are highly efficient means for recapitulating early development in vitro in order to generate organoids. The organoid technologies described here can undeniably be a valuable tool for investigating organ development and tissue morphogenesis $[13,41,49]$, for modelling diseases $[13,16,41]$, testing the efficacy and toxicity of drug compounds [10], and hopefully one day creating tissues for autologous transplantation $[15,20,22,51]$. Moreover, apart from the approaches analyzed in this review, the development of 'cancer organoids' [53] creates significant prospects for personalizing and optimizing current treatments. In the future, researchers may also develop more human organoids for the thyroid, lungs, pancreas, heart [54-58] and the sensory epithelia of the inner ear [59], using technologies that have already been applied successfully in mice.

Although it is obvious that organoid technologies have enormous potential, there are still important limitations that must be overcome. In particular, the organoids technologies so far developed have yet to be methodically characterized in terms of how faithfully they can recapitulate in vivo development. For example, while retinal organoids display typical laminar organization, outer segments fail to form, and the photoreceptors do not fully mature to become light-sensitive $[48,49]$. Likewise, cerebral organoids recapitulate fairly early events in brain development, but the typical layered structure of the mature cortical plate fails to fully form [41].

The issue of maturation is a common problem for organoid technologies, and may significantly affect future research and therapeutic potential. Although liver organoids performed liver-specific functions in vivo, such as protein production and human-specific drug metabolism, human hepatocytes were not fully differentiated, as evidenced by lower albumin secretion and lower expression of hepatocyte-specific CYP450 enzymes than previously reported for primary human hepatocytes [60]. 
Transplanted human intestinal organoids, on the other hand, have displayed mature intestine characteristics such as peptide uptake, but therapeutic application would require additional functions, such as the ability to perform the peristaltic movements essential for food bolus transition along the digestive tract [15]. Similarly, although human kidney organoids possess immature nephron- [25] and UB-like [31] structures, proper tissue patterning through successive generations of UB branching is still needed, and the nascent nephrons must link to a single draining collecting system.

Most importantly, the avascular environment in vitro is still a significant hurdle for organoids to mature to a state resembling that of adult organs. In this regard, future research will focus on developing bioreactors that can provide better nutrient exchange [41] or co-cultures with endothelial cells [22]. The most promising solution is still to transplant these tissues, as has been done with liver buds [22] and kidney organoids [25,28], which stimulates invasion from host vasculature.
In the future, organoid technologies will undoubtedly provide a methodological window, allowing us to understand human development and disease in depth, and will make it possible to personalize treatment.

\section{Acknowledgments}

The authors wish to thank Raquel Rodrigues Diez for helping with the illustration, Kerstin Mierke for proofreading and editing, and Manuela Passera for technical assistance.

The authors' research is supported by Associazione per la Ricerca sul Diabete - Italia, and by the ERC-2010-AdG-268632 RESET Grant. The authors gratefully acknowledge Bellco Srl for continue financial support.

\section{Disclosure Statement}

C.X. is a co-founder and managing director of Biorenovo Ltd.; however, he received no compensation for this role and received research funding from Bellco.

\section{References}

1 van Beijnum JR, Rousch M, Castermans K, van der Linden E, Griffioen AW: Isolation of endothelial cells from fresh tissues. Nat Protoc 2008;3:1085-1091.

-2 Sagrinati C, Netti GS, Mazzinghi B, Lazzeri E, Liotta F, Frosali F, Ronconi E, Meini C, Gacci M, Squecco R, Carini M, Gesualdo L, Francini F, Maggi E, Annunziato F, Lasagni L, Serio M, Romagnani S, Romagnani P: Isolation and characterization of multipotent progenitor cells from the bowman's capsule of adult human kidneys. J Am Soc Nephrol 2006;17: 2443-2456.

-3 Takahashi K, Yamanaka S: Induction of pluripotent stem cells from mouse embryonic and adult fibroblast cultures by defined factors. Cell 2006;126:663-676.

4 Auerbach R, Grobstein C: Inductive interaction of embryonic tissues after dissociation and reaggregation. Exp Cell Res 1958;15:384-397.

$\checkmark 5$ Moscona A, Moscona $\mathrm{H}$ : The dissociation and aggregation of cells from organ rudiments of the early chick embryo. J Anat 1952; $86: 287-301$

-6 Lewis SL, Tam PP: Definitive endoderm of the mouse embryo: formation, cell fates, and morphogenetic function. Dev Dyn 2006;235: 2315-2329.

$>7$ Rubin DC: Intestinal morphogenesis. Curr Opin Gastroenterol 2007;23:111-114.

$>8$ Sato T, Vries RG, Snippert HJ, van de Wetering $\mathrm{M}$, Barker N, Stange DE, van Es JH, Abo A, Kujala P, Peters PJ, Clevers H: Single Lgr5 stem cells build crypt-villus structures in vitro without a mesenchymal niche. Nature 2009; 459:262-265.

$\checkmark$ Sato T, van Es JH, Snippert HJ, Stange DE, Vries RG, van den Born M, Barker N, Shroyer $\mathrm{NF}$, van de Wetering $\mathrm{M}$, Clevers $\mathrm{H}$ : Paneth cells constitute the niche for Lgr5 stem cells in intestinal crypts. Nature 2011;469:415-418.

10 Dekkers JF, Wiegerinck CL, de Jonge HR, Bronsveld I, Janssens HM, de Winter-de Groot KM, Brandsma AM, de Jong NW, Bijvelds MJ, Scholte BJ, Nieuwenhuis EE, van den Brink S, Clevers H, van der Ent CK, Middendorp S, Beekman JM: A functional CFTR assay using primary cystic fibrosis intestinal organoids. Nat Med 2013;19:939-945.

-11 Sato T, Stange DE, Ferrante M, Vries RG, Van Es JH, Van den Brink S, Van Houdt WJ, Pronk A, Van Gorp J, Siersema PD, Clevers $\mathrm{H}$ : Long-term expansion of epithelial organoids from human colon, adenoma, adenocarcinoma, and Barrett's epithelium. Gastroenterology 2011;141:1762-1772.

12 Yui S, Nakamura T, Sato T, Nemoto Y, Mizutani T, Zheng X, Ichinose S, Nagaishi T, Okamoto R, Tsuchiya K, Clevers H, Watanabe M: Functional engraftment of colon epithelium expanded in vitro from a single adult $\operatorname{Lgr} 5^{+}$ stem cell. Nat Med 2012;18:618-623.

$>13$ Spence JR, Mayhew CN, Rankin SA, Kuhar MF, Vallance JE, Tolle K, Hoskins EE, Kalinichenko VV, Wells SI, Zorn AM, Shroyer NF, Wells JM: Directed differentiation of human pluripotent stem cells into intestinal tissue in vitro. Nature 2011;470:105-109.
14 Wang J, Cortina G, Wu SV, Tran R, Cho JH, Tsai MJ, Bailey TJ, Jamrich M, Ament ME, Treem WR, Hill ID, Vargas JH, Gershman G, Farmer DG, Reyen L, Martin MG: Mutant neurogenin-3 in congenital malabsorptive diarrhea. N Engl J Med 2006;355:270-280.

15 Watson CL, Mahe MM, Múnera J, Howell JC, Sundaram N, Poling HM, Schweitzer JI, Vallance JE, Mayhew CN, Sun Y, Grabowski G Finkbeiner SR, Spence JR, Shroyer NF, Wells JM, Helmrath MA: An in vivo model of human small intestine using pluripotent stem cells. Nat Med 2014;20:1310-1314.

16 McCracken KW, Catá EM, Crawford CM, Sinagoga KL, Schumacher M, Rockich BE, Tsai YH, Mayhew CN, Spence JR, Zavros Y, Wells JM: Modelling human development and disease in pluripotent stem-cell-derived gastric organoids. Nature 2014;516:400-404.

17 Zaret KS: Regulatory phases of early liver development: paradigms of organogenesis. Nat Rev Genet 2002;3:499-512.

18 Zhao R, Duncan SA: Embryonic development of the liver. Hepatology 2005;41:956-967.

19 Weiss P, Taylor AC: Reconstitution of complete organs from single-cell suspensions of chick embryos in advanced stages of differentiation. Proc Natl Acad Sci U S A 1960;46:1177-1185.

20 Huch M, Dorrell C, Boj SF, van Es JH, Li VS, van de Wetering M, Sato T, Hamer K, Sasaki N, Finegold MJ, Haft A, Vries RG, Grompe M, Clevers H: In vitro expansion of single Lgr5+ liver stem cells induced by Wnt-driven regeneration. Nature 2013;494:247-250. 
21 Huch M, Gehart H, van Boxtel R, Hamer K, Blokzijl F, Verstegen MM, Ellis E, van Wenum M, Fuchs SA, de Ligt J, van de Wetering M, Sasaki N, Boers SJ, Kemperman H, de Jonge J, Ijzermans JN, Nieuwenhuis EE, Hoekstra R, Strom S, Vries RR, van der Laan LJ, Cuppen E, Clevers H: Long-term culture of genome-stable bipotent stem cells from adult human liver. Cell 2015;160:299-312.

-22 Takebe T, Sekine K, Enomura M, Koike H, Kimura M, Ogaeri T, Zhang RR, Ueno Y, Zheng YW, Koike N, Aoyama S, Adachi Y, Taniguchi $\mathrm{H}$ : Vascularized and functional human liver from an iPSC-derived organ bud transplant. Nature 2013;499:481-484.

23 Saxen L: Organogenesis of the Kidney. New York, Cambridge University Press, 1987.

24 Dressler GR: Advances in early kidney specification, development and patterning. Development 2009;136:3863-3874.

-25 Taguchi A, Kaku Y, Ohmori T, Sharmin S, Ogawa M, Sasaki H, Nishinakamura R: Redefining the in vivo origin of metanephric nephron progenitors enables generation of complex kidney structures from pluripotent stem cells. Cell Stem Cell 2014;14:53-67.

26 Little MH, McMahon AP: Mammalian kidney development: principles, progress, and projections. Cold Spring Harb Perspect Biol 2012;pii:a008300.

27 Unbekandt M, Davies JA: Dissociation of embryonic kidneys followed by reaggregation allows the formation of renal tissues. Kidney Int 2010;77:407-416.

-28 Xinaris C, Benedetti V, Rizzo P, Abbate M, Corna D, Azzollini N, Conti S, Unbekandt M, Davies JA, Morigi M, Benigni A, Remuzzi G: In vivo maturation of functional renal organoids formed from embryonic cell suspensions. J Am Soc Nephrol 2012;23:1857-1868.

29 Xinaris C, Benedetti V, Abbate M, Conti S, Rizzo P, Novelli R, Corna D, Cavallotti D, Morigi M, Benigni A, Remuzzi G: Creating filtration structure from a suspension of embryonic kidney cells. J Am Soc Nephrol 2014; 25:170A.

30 Benedetti V, Xinaris C, Tomasoni S, Rizzo P, Novelli R, Corna D, Yokoo T, Morigi M, Benigni A, Remuzzi G: Engineering transplantable 3D renal tissue from a suspension of human amniotic fluid stem cells and mouse metanephric cells. J Am Soc Nephrol 2014;25:167A.

-31 Xia Y, Nivet E, Sancho-Martinez I, Gallegos T, Suzuki K, Okamura D, Wu MZ, Dubova I, Esteban CR, Montserrat N, Campistol JM, Izpisua Belmonte JC: Directed differentiation of human pluripotent cells to ureteric bud kidney progenitor-like cells. Nat Cell Biol 2013;15:1507-1515.

32 Takasato M, Er PX, Becroft M, Vanslambrouck JM, Stanley EG, Elefanty AG, Little MH: Directing human embryonic stem cell differentiation towards a renal lineage generates a self-organizing kidney. Nat Cell Biol 2014; 16:118-126.

33 Gilbert SF: Developmental Biology, ed 6. Sunderland, MA, Sinauer Associates, 2000.
4 Götz M, Huttner WB: The cell biology of neurogenesis. Nat Rev Mol Cell Biol 2005;6:777788.

35 Ishii K: Reconstruction of dissociated chick brain cells in rotation-mediated culture. Cytologia (Tokyo) 1966;31:89-98.

36 Watanabe K, Kamiya D, Nishiyama A, Katayama T, Nozaki S, Kawasaki H, Watanabe $\mathrm{Y}$, Mizuseki K, Sasai Y: Directed differentiation of telencephalic precursors from embryonic stem cells. Nat Neurosci 2005;8:288-296.

37 Eiraku M, Watanabe K, Matsuo-Takasaki M, Kawada M, Yonemura S, Matsumura M, Wataya T, Nishiyama A, Muguruma K, Sasai Y: Self-organized formation of polarized cortical tissues from ESCs and its active manipulation by extrinsic signals. Cell Stem Cell 2008;3: 519-532.

38 Kadoshima T, Sakaguchi H, Nakano T, Soen M, Ando S, Eiraku M, Sasai Y: Self-organization of axial polarity, inside-out layer pattern, and species-specific progenitor dynamics in human ES cell-derived neocortex. Proc Natl Acad Sci U S A 2013;110:20284-20289.

39 Danjo T, Eiraku M, Muguruma K, Watanabe K, Kawada M, Yanagawa Y, Rubenstein JL, Sasai Y: Subregional specification of embryonic stem cell-derived ventral telencephalic tissues by timed and combinatory treatment with extrinsic signals. J Neurosci 2011;31:1919-1933.

40 Suga $\mathrm{H}$, Kadoshima T, Minaguchi M, Ohgushi M, Soen M, Nakano T, Takata N, Wataya T, Muguruma K, Miyoshi H, Yonemura S, Oiso Y, Sasai Y: Self-formation of functional adenohypophysis in three-dimensional culture. Nature 2011;480:57-62.

41 Lancaster MA, Renner M, Martin CA, Wenzel D, Bicknell LS, Hurles ME, Homfray T, Penninger JM, Jackson AP, Knoblich JA: Cerebral organoids model human brain development and microcephaly. Nature 2013;501: 373-379.

42 Fuhrmann S: Eye morphogenesis and patterning of the optic vesicle. Curr Top Dev Biol 2010;93:61-84.

43 Bok D: The retinal pigment epithelium: a versatile partner in vision. J Cell Sci Suppl 1993; 17:189-195.

44 Brady RC, Hilfer SR: Optic cup formation: a calcium-regulated process. Proc Natl Acad Sci U S A 1982;79:5587-5591.

45 Layer PG, Robitzki A, Rothermel A, Willbold E: Of layers and spheres: the reaggregate approach in tissue engineering. Trends Neurosci 2002;25:131-134.

46 Stefanelli A, Zacchei AM, Ceccherini V: Retinal reconstitution in vitro after disaggregation of embryonic chicken eyes. Acta Embryol Morphol Exper 1961;4:47-55.

47 Rothermel A, Willbold E, Degrip WJ, Layer PG: Pigmented epithelium induces complete retinal reconstitution from dispersed embryonic chick retinae in reaggregation culture. Proc Biol Sci 1997;264:1293-1302.

-48 Eiraku M, Takata N, Ishibashi H, Kawada M, Sakakura E, Okuda S, Sekiguchi K, Adachi T, Sasai Y: Self-organizing optic-cup morpho- genesis in three-dimensional culture. Nature 2011;472:51-56.

-49 Nakano T, Ando S, Takata N, Kawada M, Muguruma K, Sekiguchi K, Saito K, Yonemura S, Eiraku M, Sasai Y: Self-formation of optic cups and storable stratified neural retina from human ESCs. Cell Stem Cell 2012;10:771-785.

50 Sasai Y: Next-generation regenerative medicine: organogenesis from stem cells in 3D culture. Cell Stem Cell 2013;12:520-530.

51 Assawachananont J, Mandai M, Okamoto S, Yamada C, Eiraku M, Yonemura S, Sasai Y, Takahashi M: Transplantation of embryonic and induced pluripotent stem cell-derived 3D retinal sheets into retinal degenerative mice. Stem Cell Reports 2014;2:662-674.

52 Zhu Y, Carido M, Meinhardt A, Kurth T, Karl MO, Ader M, Tanaka EM: Three-dimensional neuroepithelial culture from human embryonic stem cells and its use for quantitative conversion to retinal pigment epithelium. PLoS One 2013;8:e54552.

53 Gao D, Vela I, Sboner A, Iaquinta PJ, Karthaus WR, Gopalan A, Dowling C, Wanjala JN, Undvall EA, Arora VK, Wongvipat J, Kossai M, Ramazanoglu S, Barboza LP, Di W, Cao Z, Zhang QF, Sirota I, Ran L, MacDonald TY, Beltran H, Mosquera JM, Touijer KA, Scardino PT, Laudone VP, Curtis KR, Rathkopf DE, Morris MJ, Danila DC, Slovin SF, Solomon SB, Eastham JA, Chi P, Carver B, Rubin MA, Scher HI, Clevers H, Sawyers CL, Chen Y: Organoid cultures derived from patients with advanced prostate cancer. Cell 2014;159:176-187.

54 Antonica F, Kasprzyk DF, Opitz R, Iacovino M, Liao XH, Dumitrescu AM, Refetoff S, Peremans K, Manto M, Kyba M, Costagliola S: Generation of functional thyroid from embryonic stem cells. Nature 2012;491:66-71.

55 Lee JH, Bhang DH, Beede A, Huang TL, Stripp $\mathrm{BR}$, Bloch KD, Wagers AJ, Tseng YH, Ryeom S, Kim CF: Lung stem cell differentiation in mice directed by endothelial cells via a BMP4NFATc1-thrombospondin-1 axis. Cell 2014; 156:440-455.

56 Greggio C, De Franceschi F, Figueiredo-Larsen M, Gobaa S, Ranga A, Semb H, Lutolf M, Grapin-Botton A: Artificial three-dimensional niches deconstruct pancreas development in vitro. Development 2013;140:4452-4462.

57 Lee EJ, Kim do E, Azeloglu EU, Costa KD: Engineered cardiac organoid chambers: toward a functional biological model ventricle. Tissue Eng Part A 2008;14:215-225.

58 Mondrinos MJ, Jones PL, Finck CM, Lelkes PI: Engineering de novo assembly of fetal pulmonary organoids. Tissue Eng Part A 2014; 20:2892-2907.

-59 Koehler KR, Mikosz AM, Molosh AI, Patel D, Hashino E: Generation of inner ear sensory epithelia from pluripotent stem cells in 3D culture. Nature 2013;500:217-221.

-60 Azuma H, Paulk N, Ranade A, Dorrell C, AlDhalimy M, Ellis E, Strom S, Kay MA, Finegold M, Grompe M: Robust expansion of human hepatocytes in Fah-/-/Rag2-/-/Il2rg-/mice. Nat Biotechnol 2007;25:903-910. 